\title{
Specimen Label
}

National Cancer Institute

\section{Source}

National Cancer Institute. Specimen Label. NCI Thesaurus. Code C115528.

A set of information affixed to the sample container that contains all required information to properly and completely identify the specimen. 